\title{
NUMERICAL INVESTIGATION OF THE HYDRODYNAMIC PERFORMANCE OF THE PROPELLER BEHIND THE SHIP WITH AND WITHOUT WED
}

\author{
Alireza Nadery \\ Hassan Ghassemi \\ Amirkabir University of Technology, Tehran, Iran
}

\begin{abstract}
The presented paper numerically carries out the investigation of the hydrodynamic performance of the propeller behind the ship with and without wake equalizing duct (WED). It is mounted in front of the propeller in order to equalize the ship's wake flow and improve the propeller performance. The computational fluid dynamics (CFD) analysis software STAR-CCM solver was adopted to simulate the KP505 propeller behind the KRISO container ship (KCS) using overlapping grid technology and user-defined functions. To obtain the effect of a-duct on propeller performance, the ship bare hull case, the with-propeller case, and the with-propeller-and-duct case are also computed. Together, these computations provide for a-complete CFD comparison of the duct effects. Also, the Taguchi design of the experiment method is applied to investigate three parameters (angle of attack, trailing edge radius, and chord length) of the duct. Finally, the main dimensions are obtained, and the thrust and torque coefficients are presented and discussed for one blade and whole blades during one cycle. Based on the numerical results, it is indicated that good design increases efficiency by $1.67 \%$, and $a$-bad design may reduce efficiency by $3.25 \%$. Also, the effect of the WED caused to decrease the pressure pulse by $35.9 \%$ in the face side of the propeller blade.
\end{abstract}

Keywords: ship propeller; wake equalizing duct; hydrodynamic coefficients; Taguchi design of experiment; delivered power

\section{INTRODUCTION}

A wake equalizing duct (WED) is one of the proper and simple energy saving devices (ESDs) to use to improve propeller efficiency. It is installed in front of the propeller behind the ship hull as Figure 1. The installed duct straightens and accelerates the hull's wake into the propeller and also produces a net forward thrust. This paper focuses on the parametric investigation of the WED device for a container ship KCS.

Schneekluth first introduced these wake equalizing ducts in 1986 [2]. The aim was to optimize the overall propulsive efficiency of a ship by establishing a more uniform inflow into the propeller by accelerating the flow in the upper region of the propeller disc and by equalizing the tangential velocity components in the wake field. Schneekluth reports that the effectiveness of a WED is most evident if the ship

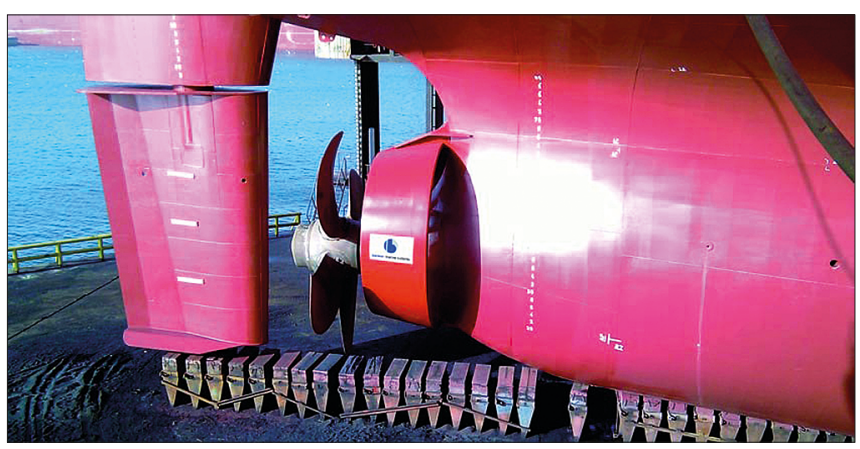

Fig. 1. The wake equalizing duct (Becker Mewis) installed on a-chemical tanker [1]

speed is between 12 and 18 knots, and its block coefficient is higher than 0.6. Friesch and Johannsen performed extensive experimental tests on a tanker with and without WED to investigate the scale effects in the HYKAT cavitation tunnel 
in the Hamburg Ship Model. In their study, it is concluded that the WED can result in a positive effect on the energy saving of the ship at full scale, but it is difficult to prove this positive effect from model tests in the same Froude number speed [3]. Also, an experimental study is performed on the effect of the WED for a general cargo ship by Korkut [4]. In his study, the influence of the hull forms and the stern flow on the wake equalizing duct is investigated. It indicates that the WED concept with an appropriate stern design affects not only the flow characteristics at the aft end but also the propulsion characteristics. A parametric study on the WED's characteristics is performed by Celik, and the angle of attack and longitudinal position of the WED for various input velocities is investigated [5]. It results that a well-designed WED can improve the propulsion characteristics of a ship considerably; otherwise, it can cause a negative effect. Go et al. numerically investigate the effect of a duct on propeller performance by considering a wide range of diameters $\left(0.7 D \leq D_{D} \leq 1.0 D\right)$ and angles of attack $\left(0^{\circ} \leq \theta \leq 20^{\circ}\right)$ of the duct. The maximum propeller efficiency is achieved in the case of $D_{D}=0.7 D$ at $\theta=20^{\circ}[6]$.

A wake equalizing duct can be combined with a pre-swirl stator (PSS) to reduce both axial and rotational loss. Mewis first combined a WED with a PSS and shows that it can result in energy savings of 7-9 percent [7]-[9]. The pre-swirl duct (PSD) aims to bring uniformity to the propeller inflow and reduce the rotational losses in the slipstream of the propeller by the pre-swirl stators. Dang et al. [10], [11] investigated the effects of three different ESDs of PSD, PSS and propeller boss cap fins (PBCFs) on propeller performance using CFD and particle image velocimetry (PIV) tests. Two kinds of PSD, i.e., unconventional half circular duct and conventional circular pre-swirl duct, a for VLCC ship with large block coefficients is investigated using experiments and CFD [12]. Kim [13] studied a new PSD for 317 KVLCC and indicated that using this PSD results in improving the propulsive efficiency by recovering the wake fraction. Hanaoka [14] predicted the open-water thrust and torque of propellers equipped with a PSD at the different distance of the propeller and duct using the quasicontinuous method and indicated that different distances of duct in front of the propeller have an insignificant impact on open-water characteristics of the propeller. Three types of PSD are compared using CFD and experiment, showing that the Mewis duct provides the highest value of thrust and torque coefficients at higher advance ratios [15]. Recently, Nadery and Ghassemi numerically investigated the hydrodynamic performance of the propeller under oscillating flow [16] and behind the ship with and without PSS [17].

According to the best of our knowledge, the effects of the three duct parameters - the angle of attack, duct radius, and duct chord length - on the propulsion performance of a -conventional ship have not been studied together so far. Moreover, the study gap related to the investigation of ship propulsion behavior under different types of duct parameters is detectable. Additionally, one can conclude that the performance of duct parameters depends on each other. Therefore, the main purpose of the present study is to evaluate the influences of three duct parameters, i.e., angle of attack, duct radius, and duct chord length, by CFD simulations.

The rest of this paper is structured as follows. In Section 2, governing equations and geometries are described. Numerical results of the ship bare hull and the hydrodynamic performance of the propeller behind the ship hull with and without WED are presented and discussed in Section 3. Finally, the conclusion is presented in Section 4.

\section{GOVERNING EQUATIONS AND GEOMETRIES}

Reynolds averaged Navier-Stokes (RANS) equations and the continuity equation are governed in the three-dimensional computational domain for an incompressible flow. These equations can be written in a Cartesian tensor form as:

$$
\begin{gathered}
\frac{\partial u_{i}}{\partial x_{i}}=0 \\
\frac{\partial}{\partial t}\left(\rho u_{i}\right)+\frac{\partial}{\partial x_{i}}\left(\rho u_{i} u_{j}\right)= \\
-\frac{\partial p}{\partial x_{i}}+\frac{\partial}{\partial x_{j}}\left[\mu\left(\frac{\partial u_{i}}{\partial x_{j}}-\rho \overline{u_{i}^{\prime} u_{j}^{\prime}}\right)\right]
\end{gathered}
$$

where $x_{i}$ is the Cartesian coordinates, $u_{i}$ is the corresponding velocity components, and $p, \rho$ and $\mu$ are the static pressure, density, and molecular viscosity, respectively. $-\rho \overline{u_{i}^{\prime} u_{j}^{\prime}}$ is the Reynolds stress. The Reynolds stress must be modeled to solve the governing equation by using an appropriate turbulence model. The $k-\varepsilon$ turbulence model was used to solve the Reynolds stress term of $-\rho \overline{u_{i}^{\prime} u_{j}^{\prime}}$ and the rigid body motion (RBM) scheme was adopted for the rotation of the propeller. The dynamic fluid body interaction (DFBI) module was used to simulate the motion of the ship body in response to forces exerted by the flow pattern.

In the present study, STAR-CCM+ commercial software is used which discretizes the continuous equations using the finite volume method (FVM). This method employs discretization of the integral form of the conservation equations directly in physical space. Therefore, the resulting equations express the exact conservation of relevant fluid characteristics for each finite cell volume. FVM is suitable for all mesh types (structured, unstructured or hybrid), and it is valid for an arbitrary shape of cells, which makes it suitable for complex geometries. It has to be noted that the mesh, which divides the solution domain into a finite number of contiguous control volumes, defines actually only the control volume boundaries, so it does not have to be related to a specific coordinate system.

Discretization of governing flow equations results in a large system of nonlinear algebraic equations. The method of their solution depends on the problem, but in all cases, since the equations are nonlinear, an iterative solution approach is required. The iterative approaches use successive linearization of the equations, and the resulting linear systems are solved, as a rule, by iterative techniques. Special algorithms are used to ensure correct coupling between pressure and velocity. 
As with any iterative approach, solution algorithms in CFD need a set of convergence criteria to control convergence. It is customary to distinguish the two levels of iterations: inner iterations, within which the linear equation systems are solved, and outer iterations that deal with nonlinearity of the problem and coupling of the equations. Convergence monitoring on both levels is very important as it tells the user whether the desired converged solution is obtained and when it is possible to stop the iterative process. Further details of the implementation can be found in the STAR-CCM+ manuals [18], [19].

The results from the simulation with regard to the thrust coefficient $\left(K_{T}\right)$, torque coefficient $\left(K_{Q}\right)$, efficiency $(\eta)$, advance coefficient $(J)$ and delivered power $\left(P_{D}\right)$ are expressed mathematically as follows:

$$
\begin{aligned}
K_{T} & =\frac{T}{\rho n^{2} D^{4}} \\
K_{Q} & =\frac{Q}{\rho n^{2} D^{5}} \\
\eta & =\frac{J}{2 \pi} \frac{K_{T}}{K_{Q}} \\
J & =\frac{V_{a}}{n D} \\
P_{D} & =2 \pi \mathrm{nQ}
\end{aligned}
$$

where $\rho$ is the density of water, $n$ is revolutions per second of the propeller, $D$ is the diameter of the propeller, and $V_{a}$ is the velocity of advance.

\section{GEOMETRICAL PROPERTIES}

The KRISO container ship (KCS) is a modern container ship with a bulbous bow used to explore conceptual data in flow physics as well as validate CFD models [20]. The ship is equipped with the KP505 propeller. The geometry of the KCS and the KP505 propeller are shown in Figure 2, and details of the dimensions and geometrical properties are listed in Table 1.
Tab. 1. Main dimensions of the model propeller (KP505) and KCS

\begin{tabular}{|c|c|c|c|}
\hline \multicolumn{2}{|c|}{ KRISO container ship (KCS) } & \multicolumn{2}{c|}{ Propeller KP505 } \\
\hline LPP & $7.728[\mathrm{~m}]$ & Diameter (D) & $250[\mathrm{~mm}]$ \\
\hline LWL & $7.357[\mathrm{~m}]$ & No. of blades & 5 \\
\hline BWL & $1.019[\mathrm{~m}]$ & $\begin{array}{c}\text { Pitch ratio } \\
\text { (mean) }\end{array}$ & 0.950 \\
\hline$D$ & $0.6013[\mathrm{~m}]$ & Hub ratio & 0.180 \\
\hline$T$ & $0.3418[\mathrm{~m}]$ & $\begin{array}{c}\text { Expanded area } \\
\text { ratio }\end{array}$ & 0.80 \\
\hline $\begin{array}{c}\text { Displacement } \\
\text { volume }\end{array}$ & $1.649\left[\mathrm{~m}^{3}\right]$ & Section type & NACA66 \\
\hline
\end{tabular}

\section{TAGUCHI APPROACH}

In Taguchi's approach, the optimum design is determined by using design of experiment principles, and consistency of performance is achieved by carrying out the trial conditions under the influence of the noise factors. The highest possible performance is obtained by determining the optimum combination of design factors. After the factors and levels are determined, the appropriate orthogonal array is selected, and each trial condition is described. Finally, analysis is performed to determine the following:

- The optimum design.

- Influence of individual factors.

- Performance at the optimum condition and confidence interval.

The analysis of variance (ANOVA) is the statistical treatment most commonly applied to the results of the experiment to determine the relative percentage influence of an individual factor and to separate the significant factors from the insignificant ones. To optimize the propeller efficiency (larger is better), the signal-to-noise ratio which is based on larger is better used as follows.

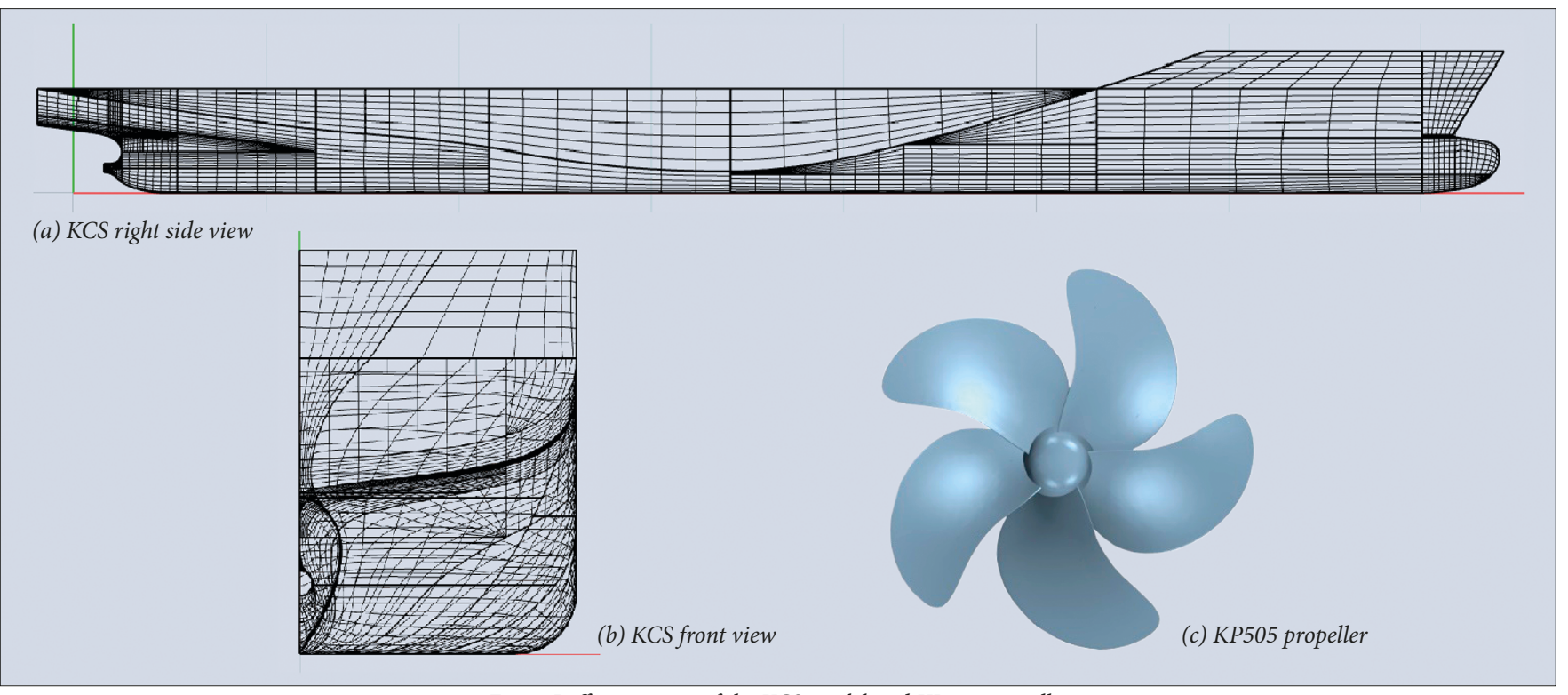

Fig. 2. Different views of the KCS model and KP505 propeller 


$$
\frac{S}{N}=-10 \log _{10}\left(\frac{1}{N} \times \sum \frac{1}{\eta_{i}^{2}}\right)
$$

where $N$ is the number of the calculation result, and $\eta_{i}$ is the efficiency of each trial.

\section{NUMERICAL RESULTS}

\section{MESH SENSITIVITY ANALYSIS}

Accurate CFD results depend on generated proper meshes. For this purpose, after some reviews, it was concluded that the unstructured trimmed mesh is better to calculate the thrust, torque, and flow field around the propeller [21]. So, we used a trimmed mesh method with a 1.3 surface growth rate and a fast volume growth rate. With these settings, the results have been achieved with a smaller number of meshes.

For the grid study, the convergence analysis (GCI) proposed by Celik et al. [22] the Fluids Engineering Division of ASME has pursued activities concerning the detection, estimation and control of numerical uncertainty and/or error in computational fluid dynamics (CFD is performed to achieve mesh-independent results. The results are obtained from the four mesh sizes (coarse, medium, fine and finer). Based on this method, proper verification is performed on the grid generation analysis. As shown in Table 2, the total thrust $(T)$ is computed, and the uncertainty is obtained as $G C I_{\text {finer }}^{21}=0.0018 \%$. All numerical computations are performed on a computer with 6 cores and 12 logical processors $(4.6 \mathrm{GHz}$ Intel processors) and 32 GB RAM. Convergence is achieved within almost 19 hours of computation. Finally, based on Figure 3 and Table 2, it is discovered that 2.6 million meshes is proper choice as the final mesh based on the acceptable error and the simulation time.

\begin{tabular}{|c|c|c|c|}
\hline$N_{1}$ (finer) & 4296378 & $N_{3}($ medium $)$ & 1485082 \\
\hline$N_{2}($ fine $)$ & 2660011 & $N_{14}($ coarse $)$ & 991875 \\
\hline$h_{1}$ & 0.013918273 & $h_{3}$ & 0.019832131 \\
\hline$h_{2}$ & 0.016330208 & $h_{4}$ & 0.022688226 \\
\hline$r_{21}$ & 1.173292651 & $r_{32}$ & 1.214444482 \\
\hline$\varphi_{1}$ & 82.83274574 & $\varphi_{3}$ & 82.75646501 \\
\hline$\varphi_{1}$ & 81.60108308 & $\varphi_{4}$ & 80.52430142 \\
\hline$\varepsilon_{21}$ & -0.076280732 & $\varepsilon_{32}$ & -1.155381929 \\
\hline$q$ & -0.520130864 & $p$ & 13.75120212 \\
\hline$\varphi^{21}{ }_{\text {ext }}^{21}$ & 82.84227643 & $e^{21}{ }_{a}$ & $0.092090068 \%$ \\
\hline$e^{21}{ }_{e x t}$ & 0.011504621 & $G C I^{21}$ fine & $0.014382431 \%$ \\
\hline
\end{tabular}

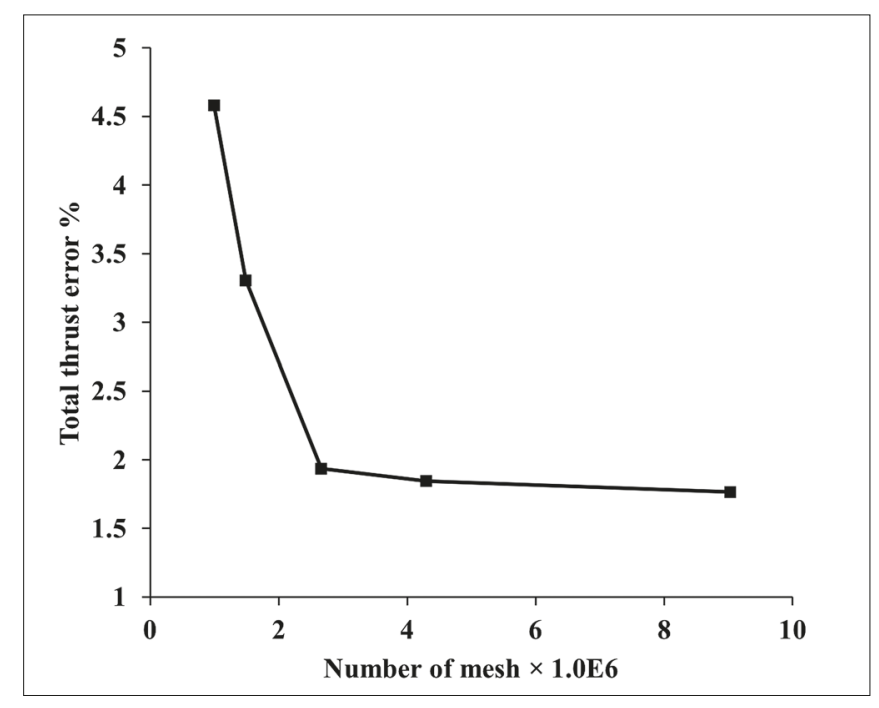

Fig. 3. Mesh dependency $V_{s}=2.196 \mathrm{~m} / \mathrm{s}$ and $n=9.5 \mathrm{RPS}$

First, the numerical flow analyses around the ship without propeller and duct are performed to obtain the nominal wake distribution. Then, the flow analyses for all cases of the ship with propeller and duct are carried out. Also, to reduce the required CPU time, the aft body of the ship is taken into account rather than the full body in the case with propeller and duct, and the captured nominal wake is used as input flow to the simulations. Figure 4 illustrates both the ship and aft body of the ship with propeller and duct.

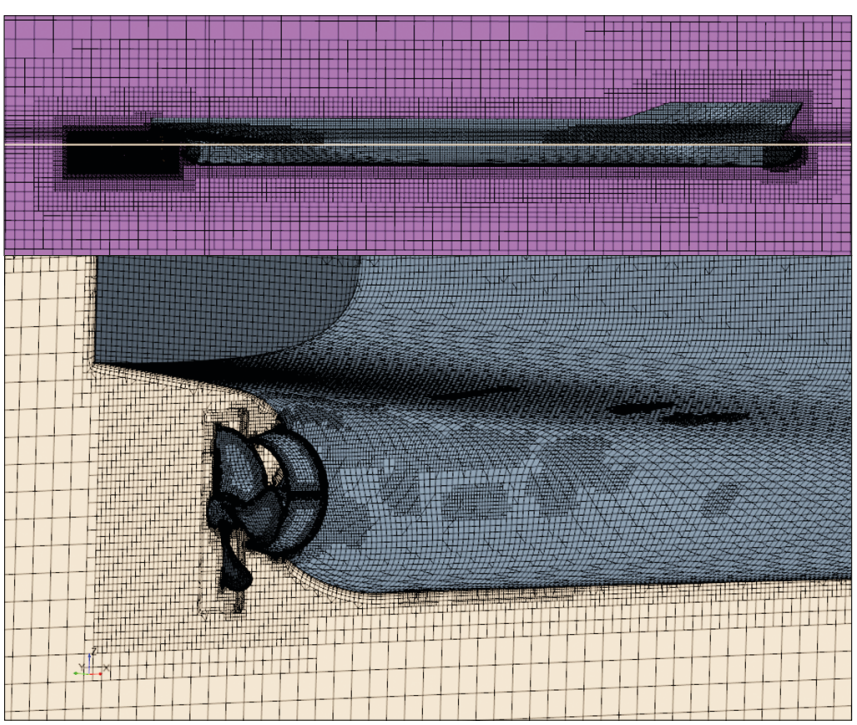

Fig. 4. Computational mesh for both ship and aft body of ship with propeller and duct

To accurately resolve the boundary layer and provide desired levels of wall $y+$, five layers of prismatic cells are placed. The total thicknesses of the prism layers are 1.9, 4, and 15 millimeters, respectively, for propeller blades, duct, and ship body surface. Also, the prism layer near-wall thicknesses are $0.15,0.51$, and 1 millimeter for propeller blades, duct, and ship, respectively. With such settings of the boundary layer, the mesh achieves the $y+$ values less than 54 . The selected time step has been calculated in such a way that 
the propeller rotates between 0.5 and 2 degrees per time step according to International Towing Tank Conference (ITTC) recommendation [23]. Here, in our numerical approach, the time step is $0.0005 \mathrm{~s}$ for the case with the propeller, which allows the propeller to rotate 1.9 degrees, and the time step is $0.04 \mathrm{~s}$ for the ship without the propeller.

\section{BARE HULL CONDITION}

The KRISO container ship (KCS) with $7.7 \mathrm{~m}$ length is simulated, and the calculations are performed at design ship speed $(2.196 \mathrm{~m} / \mathrm{s})$. Figure 5 shows the free surface waves after 160 seconds when the result converges. The nominal wake has been captured at a section and used as an input flow for the following sections. Table 3 shows the total ship resistance, wake factor, and resistance coefficient. To validate the ship resistance coefficient, the experimental resistance coefficient is 0.003711 , and the CFD calculated resistance coefficient is 0.003636 , which shows an error of 2.03 percent that is acceptable.

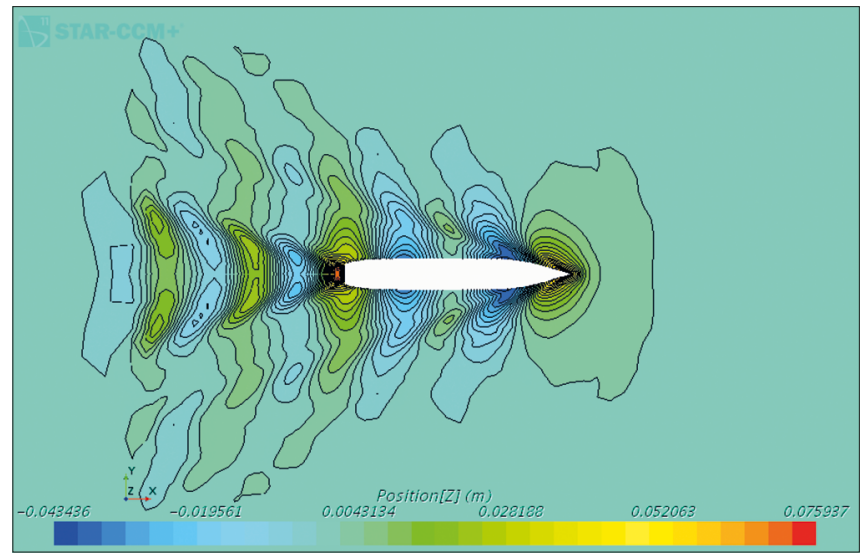

Fig. 5. Free surface waves at $V_{s}=2.196 \mathrm{~m} / \mathrm{s}$

Tab. 3. Total ship resistance, wake factor and validation of resistance coefficient

\begin{tabular}{|c|c|c|c|c|c|c|}
\hline $\begin{array}{c}\mathrm{Vs} \\
{[\mathrm{m} / \mathrm{s}]}\end{array}$ & $\mathrm{RT}[\mathrm{N}]$ & $\begin{array}{c}\mathrm{Va} \\
{[\mathrm{m} / \mathrm{s}]}\end{array}$ & $\mathrm{w}[-]$ & $\begin{array}{c}\text { Num } \\
\mathrm{CD}[-]\end{array}$ & $\begin{array}{c}\text { Exp CD } \\
{[-]}\end{array}$ & $\begin{array}{c}\text { CD Error } \\
{[\%]}\end{array}$ \\
\hline 2.196 & 83.0648 & 1.8000 & 0.1803 & 0.003636 & 0.003711 & 2.03 \\
\hline
\end{tabular}

\section{WITH PROPELLER CONDITION}

The wake field is recorded and extracted, as velocity components and their coordinates, at a section, around the mid-ship section, by creating a square plate the same size as the inlet section. Figure 6 clearly shows this wake and the boundary layer of the modeling ship at the inlet section. In fact, by taking the wake from a separate simulation and using it as input, we have a wake current with a boundary layer at the same inlet section instead of a constant current. This current enters the propeller after passing through the aft body of the ship. Figure 7 compares the axial velocity at upstream of the propeller after 4 seconds (about 40 propeller revolutions) with the calculated velocity by Wong [1] at a self-propulsion test. From this figure, it is concluded that the flow at the top of the impeller has decreased further.

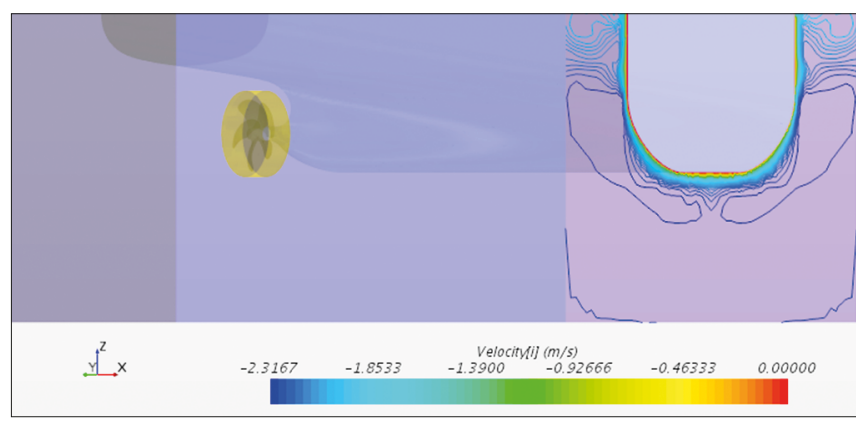

Fig. 6. Simulation of the aft body of the ship with propeller and input nominal wake

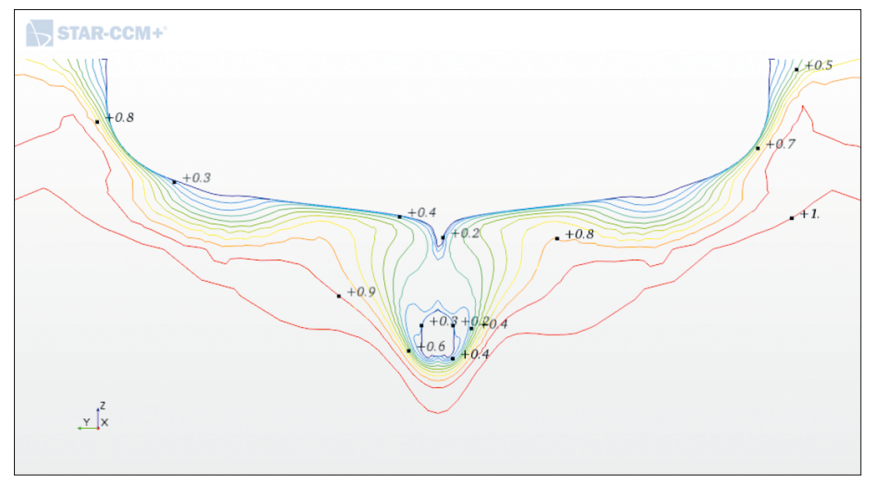

(a) Calculated wake

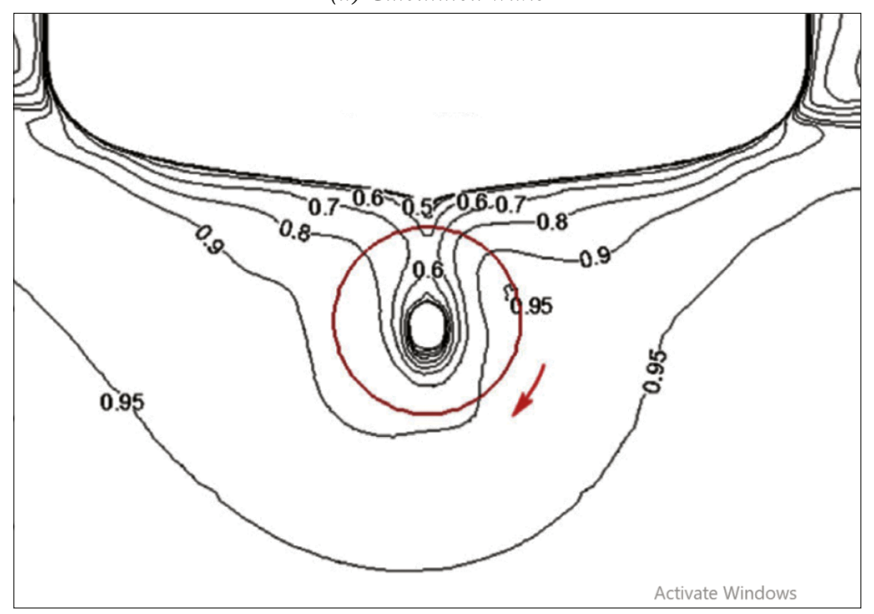

(b) Calculated wake by Wong [24]

Fig. 7. Comparison of nondimensional axial velocity at 0.3 diameters upstream of the propeller plane

\section{WITH PROPELLER AND DUCT CONDITION}

Based on the results of the previous section, the duct axis is 0.2 times the propeller radius higher than the shaft axis, as can be seen in Figure 8. The duct profile may also generate very small thrust, but the main task is to equalize the ship's wake, so for this reason it is called WED. NACA-3309 is selected for the duct profile, and the distance of the duct trailing edge from the propeller is 0.4 times the propeller radius $(0.4 R)$. The duct is adjoined to the lower part of the shaft with a connector stator. The chord length of the connector stator is $0.16 R$ and has a NACA0006 symmetrical cross-section. In this paper, three parameters of the duct (angle of attack, duct chord length, and duct radius) are investigated in three levels in Table 4. 


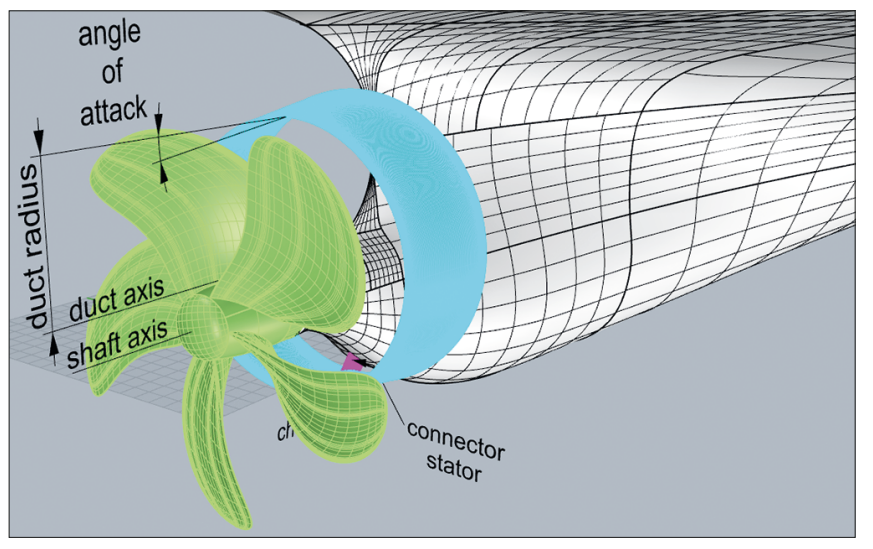

(a) $3 D$ view

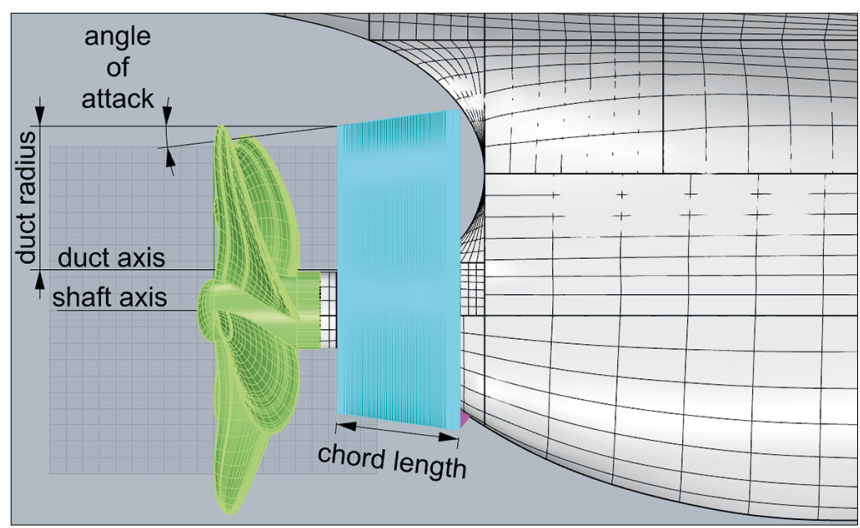

(b) Side view

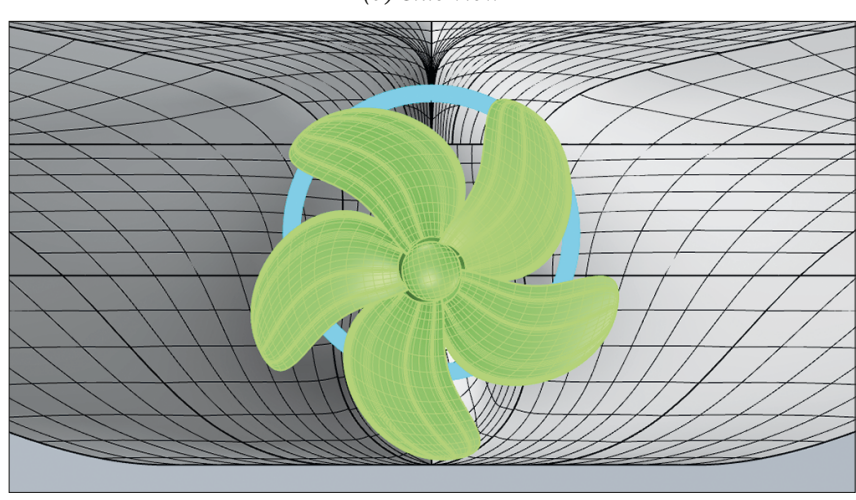

(c) Back view

Fig. 8. Different perspective views of the propeller duct behind the ship

Tab. 4. Duct parameters and levels

\begin{tabular}{|c|c|c|c|}
\hline Level number & $\begin{array}{c}\text { Chord } \\
\text { length }\end{array}$ & $\begin{array}{c}\text { Angle of attack } \\
\text { [deg.] }\end{array}$ & $\begin{array}{c}\text { Trailing } \\
\text { radius }\end{array}$ \\
\hline Level 1 & $0.4 R$ & 7 & $0.5 R$ \\
\hline Level 2 & $0.5 R$ & 10 & $0.6 R$ \\
\hline Level 3 & $0.6 R$ & 13 & $0.7 R$ \\
\hline
\end{tabular}

${ }^{*} R$ is propeller radius

Examining three parameters at three levels requires $\left(3^{3}\right)$ 27 simulations. To reduce the computational cost, the Taguchi method and its orthogonal array are used to arrange the simulations. Table 5 shows the level of each parameter in simulations, and Table 6 shows the results.
Here, the calculations are based on the thrust identity, which means total thrust $\left(T_{\text {total }}+T_{\text {prop }}+T_{\text {duct }}\right.$, where $T_{\text {duct }}$ is the thrust of duct) and advance speed $\left(V_{a}\right)$ are the same in the case of the propeller with and without WED. In order to adapt this condition, the propeller rotation speed is changed to reach the same thrust. In the case of WED, it is difficult to find $n$ to reach the same thrust. The rotating speed of the propeller $(n)$ is calculated by trial and error and is time-consuming.

Figure 9 shows the sensitivity of the answer to the parameters. From the gradient of the graphs, it can be seen that the change in the angle of attack has the most effect on the efficiency results. Although the Taguchi method predicts a level of each parameter, as shown in Table 6, the power diminishes and efficiency increases with WED in simulation 7 more than others. Table 6 also shows that the simulation 8 gives the reduction of efficiency of $3.25 \%$ by duct effect, while in the case of simulation 7 , the efficiency is increased by $1.671 \%$. Thus, according to Table 5 , the final geometries of the duct are found and given in Table 7.

Tab. 5. Taguchi orthogonal array $(3 \times 3)$

\begin{tabular}{|c|c|c|c|}
\hline $\begin{array}{c}\text { Simulation } \\
\text { number }\end{array}$ & $\begin{array}{c}\text { Level of chord } \\
\text { length }\end{array}$ & $\begin{array}{c}\text { Level of } \\
\text { angle of attack }\end{array}$ & $\begin{array}{c}\text { Level of trailing } \\
\text { radius }\end{array}$ \\
\hline 1 & 1 & 1 & 1 \\
\hline 2 & 1 & 2 & 2 \\
\hline 3 & 2 & 3 & 2 \\
\hline 4 & 2 & 2 & 3 \\
\hline 5 & 2 & 3 & 3 \\
\hline 6 & 3 & 1 & 2 \\
\hline 7 & 3 & 3 & 1 \\
\hline 8 & & & 3 \\
\hline
\end{tabular}

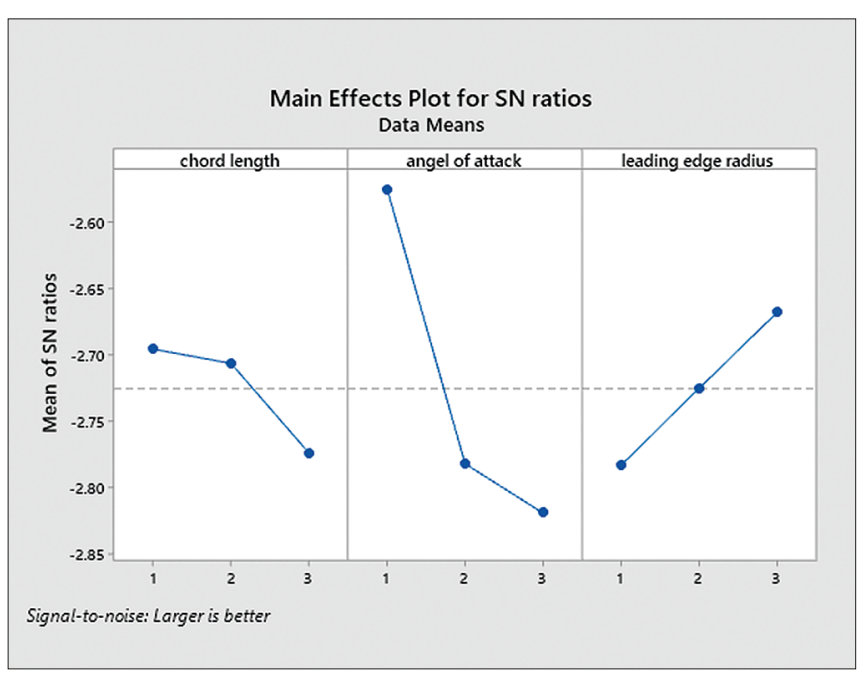

Fig. 9. Influence of individual parameters 
Tab. 6. Performance of the propeller behind the ship with and $w / o-W E D$ at $V_{s}=2.196 \mathrm{~m} / \mathrm{s}$

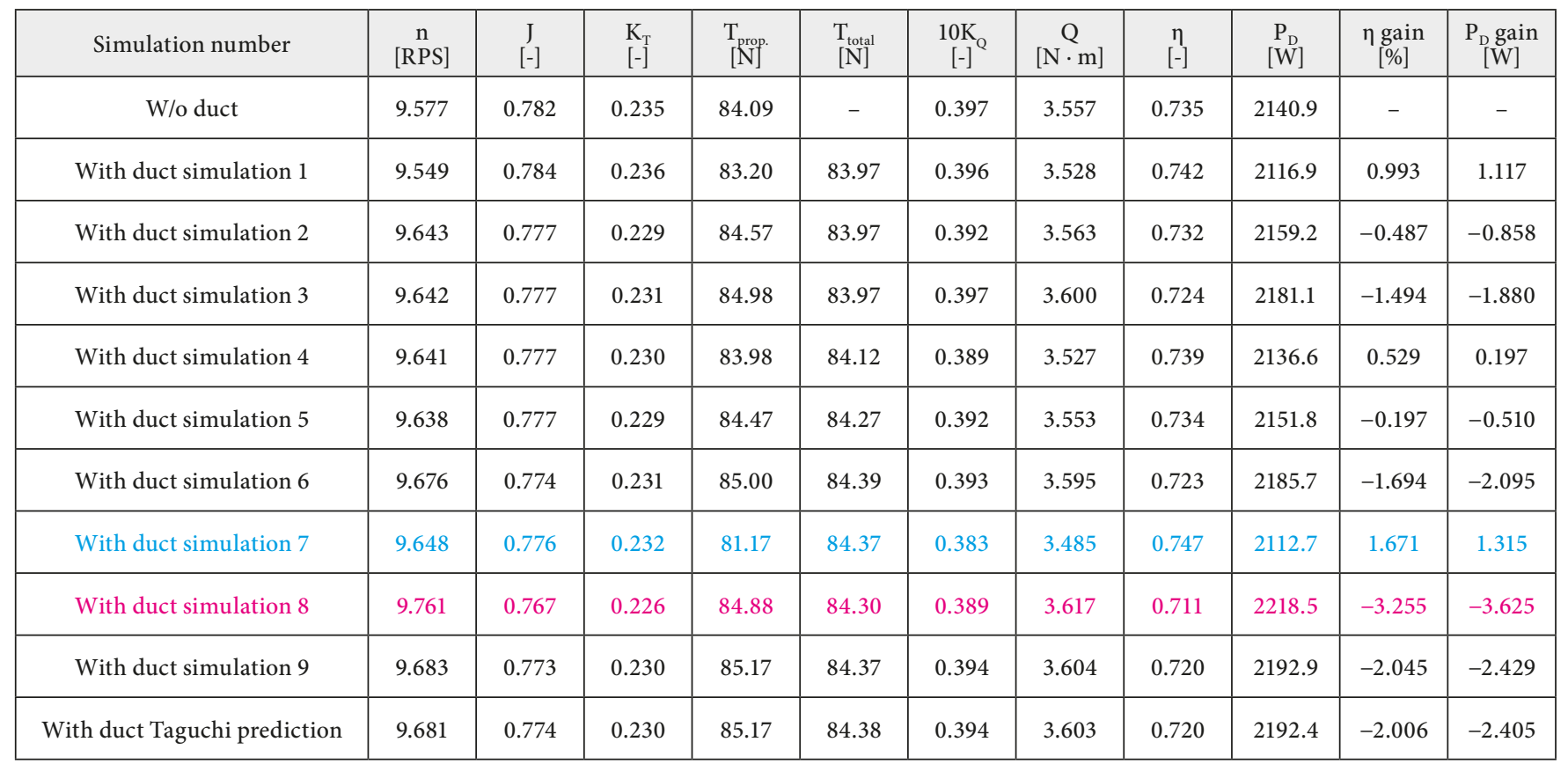

Tab. 7. Final dimensions of the WED

\begin{tabular}{|c|c|}
\hline Parameter & Value \\
\hline Section type & NACA-3309 \\
\hline Distance of duct axis from shaft axis & $0.2 R$ \\
\hline Chord length & $0.6 R$ \\
\hline Trailing radius & $0.7 R$ \\
\hline Angle of attack [deg.] & 7 \\
\hline
\end{tabular}

\section{COMPARISON AND DISCUSSION}

In Figure 10, axial (isolines) and cross velocities (vector) for the bare hull, with propeller condition, and with propeller and WED condition are presented at a distance from the propeller $(x=0.2 \mathrm{D})$ in the upstream of the propeller. As can be observed, the WED has changed the flow into the propeller and has increased the axial velocity in the upper region of the propeller disc.
Figure 11 shows the pressure distribution contours at the back side and face side of the propeller with and without $\mathrm{WED}$ at $V_{a}=1.8 \mathrm{~m} / \mathrm{s}$. As shown, it is evident that high pressure is found at the face side or pressure side, and low pressure is shown in the back or suction side. In this figure, the maximum and minimum amounts of the pressure show that the WED decreases maximum pressure in the face side and minimum pressure in the back side. The pressure is also shown in the four last cycles on the blade surface at the position of $x / C=0.4$ and $r=0.7 R$ in Figure 12. In this calculation, the propeller rotational speed is $9.577 \mathrm{RPS}$, and during 3 seconds the propeller is rotated 28 revolutions, means each rotation is $0.107 \mathrm{~s}(0.107$ cycles/second). The pressure is given in the last four cycles. In the case of using WED, the duct provides a decrease in the amplitude of pressure by 35.9 percent in the face side.

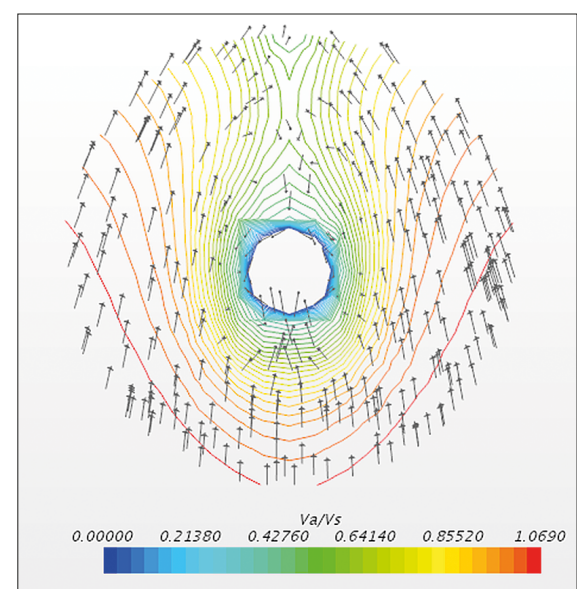

(a) Bare hull condition

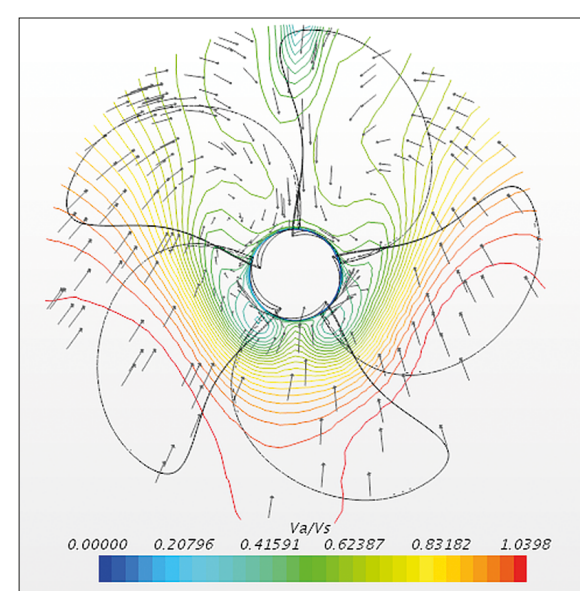

(b) With propeller condition

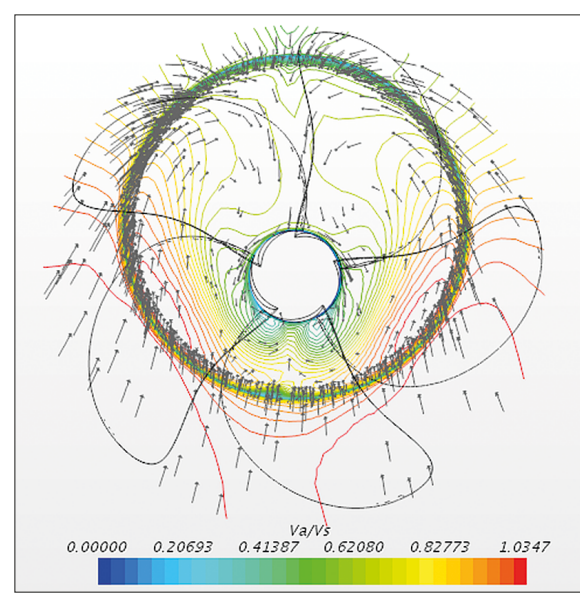

(c) With propeller and WED condition

Fig. 10. Axial (isolines) and cross velocities (vector) for bare hull (a), with propeller condition $(b)$ and with propeller and WED condition $(c)$ at $x / D=0.2$ and $V_{a}=1.8 m / s$ 


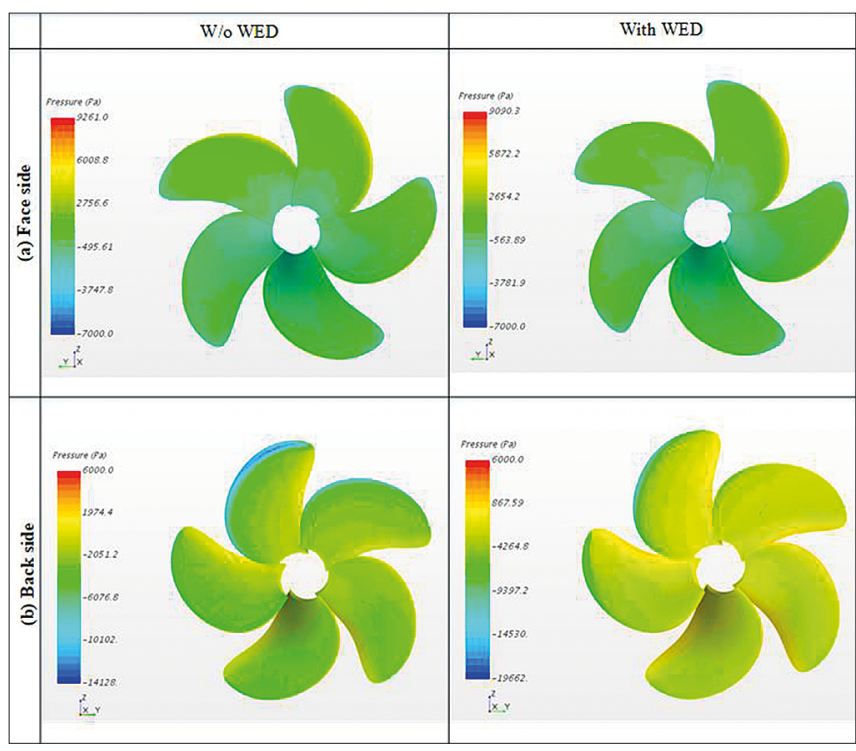

Fig. 11. Pressure distribution contours on propeller surfaces at $V_{a}=1.8 \mathrm{~m} / \mathrm{s}$

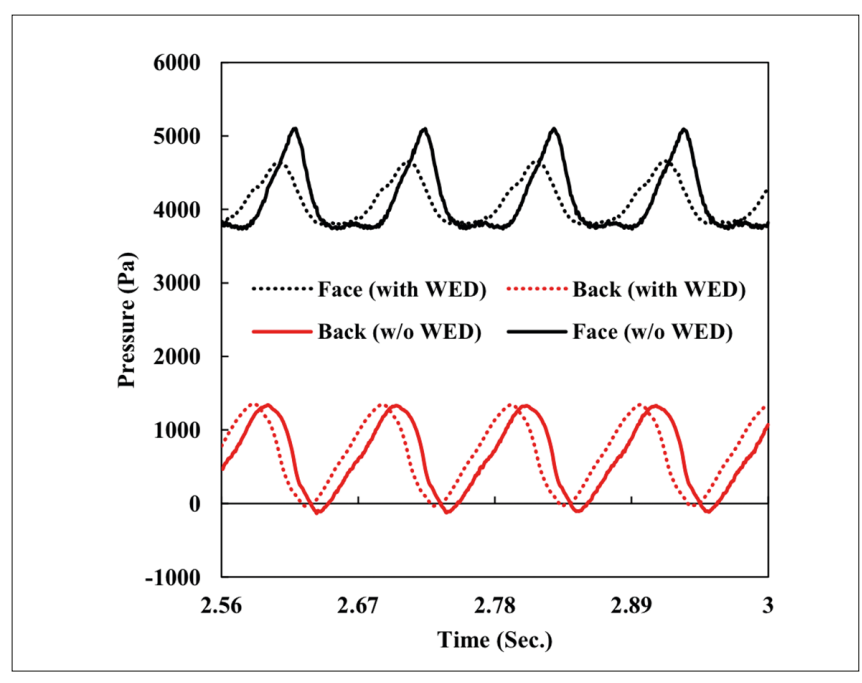

Fig. 12. Fluctuating pressure for four cycles at $r / R=0.7$ and $x / C=0.4, V_{a}=1.8 \mathrm{~m} / \mathrm{s}$
Thrust and torque coefficients against one cycle for one blade and whole blades with and without WED at an advance speed $\left(V_{a}=1.8 \mathrm{~m} / \mathrm{s}\right)$ are shown in Figure 13. As can be seen in the one-blade case (Figure 13-A), the amplitude of thrust and torque is diminished during one cycle. Total thrust and torque fluctuations are decreased, and the results are smoother with WED. Also, the effect of WED diminishes the mean of the torque coefficient at the same thrust coefficient.

\section{CONCLUSION}

This study numerically investigated the hydrodynamic performance of the propeller behind the ship with and without WED. To obtain the effect of the duct on propeller performance, the ship bare hull case, the with-propeller case, and the with-propeller-and-duct case were computed. Also, WED parameters were investigated, and propeller hydrodynamic performance was compared with and without the WED. The results of the present study lead to the following conclusions:

- The effect of the WED caused to increase the axial velocity in the upper region of the propeller disc.

- Efficiency is increased and delivered power is decreased by the WED.

- The maximum efficiency of the propeller is achieved by the duct when the dimensions of the chord is $0.6 R$, the angle of attack is 7 degrees, and the radius of the duct is $0.7 R$.

- In order to converge results, the propeller is rotated 28 revolutions during 3 seconds ( 0.107 cycles/second). In case of the using duct, the amplitude of the pressure pulse decreases by 35.9 percent in the face side.

- Total thrust and torque fluctuations are decreased, and the results are smoother with the WED.

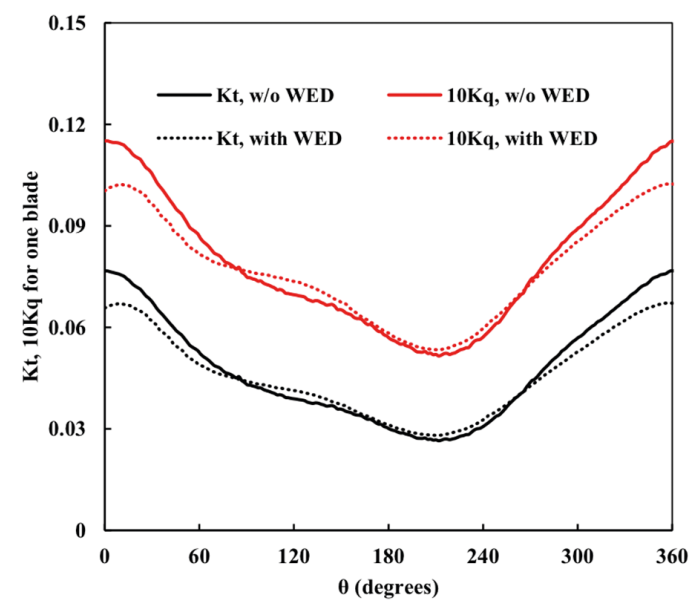

A-One blade

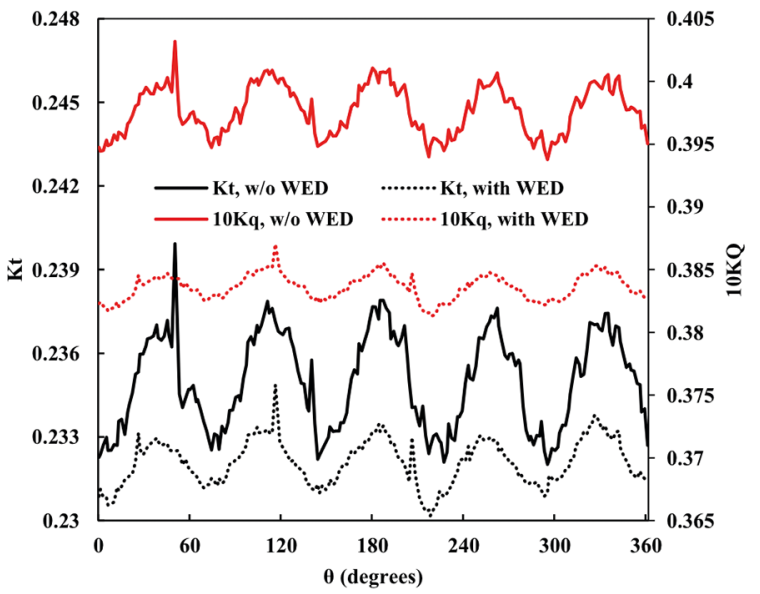

B-whole blades

Fig. 13. Comparison of thrust and torque coefficients in one cycle for (A) one-blade and (B) whole blades with and without WED 


\section{REFERENCES}

1. “The Becker Mewis Duct.” [Online]. Available: http://www. baltmarine.eu/becker-marine-systems

2. H. Schneekluth, "Wake equalising ducts," The Naval Architect, 1986.

3. J. Friesch and C. Johannsen, "Propulsion optimization tests at high Reynolds numbers," in SNAME Trans, 1994, pp. 1-21.

4. E. Korkut, "A -case study for the effect of a -flow improvement device (a -partial wake equalizing duct) on ship powering characteristics," Ocean Engineering, vol. 33, no. 2, pp. 205-218, Feb. 2006.

5. F. Çelik, "A -numerical study for effectiveness of a -wake equalizing duct," Ocean Engineering, vol. 34, no. 16, pp. $2138-2145,2007$.

6. J. S. Go, H. S. Yoon, and J. H. Jung, "Effects of a-duct before a -propeller on propulsion performance," Ocean Engineering, vol. 136, pp. 54-66, May 2017.

7. F. Mewis and H. Peters, "Power savings through a -novel fin system," in SMSSH Conference, 1986, p. 9.

8. F. Mewis, "Development of a -novel power-saving device for full-form vessels," HANSA International Maritime Journal, vol. 11, no. 145, 2008.

9. F. Mewis, "A -novel power-saving device for full-form vessels," in First International Symposium on Marine Propulsors, June 2009.

10. J. Dang, H. Chen, G. Dong, A. Ploeg, R. Hallmann, and F. Mauro, "An exploratory study on the working principles of energy saving devices (ESDs) - PIV, CFD investigations and ESD design guidelines," in 31st International Conference on Ocean, Offshore and Arctic Engineering OMAE2012, 2012.

11. J. Dang, H. Chen, D. Guoxiang, A. Van Der Ploeg, R. Hallmann, and F. Mauro, "An exploratory study on the working principles of energy saving devices (ESDs)," Symposium on Green Ship Technology (Greenship'2011), October, 2011.

12. H. J. Shin, J. S. Lee, K. H. Lee, M. R. Han, E. B. Hur, and S. C. Shin, "Numerical and experimental investigation of conventional and un-conventional preswirl duct for VLCC," International Journal of Naval Architecture and Ocean Engineering, vol. 5, no. 3, pp. 414-430, 2013.

13. J. H. Kim, J. E. Choi, B. J. Choi, S. H. Chung, and H. W. Seo, "Development of energy-saving devices for a -full slowspeed ship through improving propulsion performance," International Journal of Naval Architecture and Ocean Engineering, vol. 7, no. 2, pp. 390-398, 2015.
14. A. Hanaoka, Y. Kawanami, and M. Hinatsu, "Application of quasi-continuous method to open-water characteristics predictions of propellers with energy-saving ducts," International Journal of Offshore and Polar Engineering, vol. 26, pp. 72-80, 2016.

15. H. Nowruzi and A. Najafi, "An experimental and CFD study on the effects of different pre-swirl ducts on propulsion performance of series 60 ship," Ocean Engineering, vol. 173, no. 424, pp. 491-509, 2019.

16. A. R. Nadery and H. Ghassemi, "Hydrodynamic performance of the ship propeller under oscillating flow with and without stator," American Journal of Civil Engineering and Architecture, vol. 8, no. 2, pp. 56-61. 2020.

17. A. R. Nadery and H. Ghassemi, "Toward the hydrodynamic performance of the propeller behind the ship by pre-swirl stator", Proceedings of the Institution of Mechanical Engineers, Part M: Journal of Engineering for the Maritime Environment, revised under review.

18. CD-Adapco, “User Guide STAR-CCM+.” 2014.

19. J. Felicjancik, P. Król, and B. Tomasz, "Experimental and computational analysis of the ship propeller in open water conditions for inclined flow," Nutts'16 19th Numerical Towing Tank Symposium, pp. 26-31, 2016.

20. P. M. Carrica, H. Fu, and F. Stern, "Computations of selfpropulsion free to sink and trim and of motions in head waves of the KRISO Container Ship (KCS) model," Applied Ocean Research, vol. 33, no. 4, pp. 309-320, 2011.

21. Y. Huilan, Z. Huaixin, and Y. Chao, "Comparison of three automatic unstructured mesh types in the simulations of a propeller from global forces to flow field details," Shanghai, China, 2002.

22. I. B. Celik, U. Ghia, P. J. Roache, C. J. Freitas, H. Coleman, and P. E. Raad, "Procedure for estimation and reporting of uncertainty due to discretization in CFD applications," Journal of Fluids Engineering, vol. 130, no. 7, pp. 078001-078004, 2008.

23. ITTC Procedings, "Practical Guidelines for Ship CFD Applications ITTC - Recommended Procedures and Guidelines, section 7.5-03-02-03," in International Towing Tank Conference, 2014

24. C. Wang, S. Sun, L. Li, and L. Ye, "Numerical prediction analysis of propeller bearing force for full-scale hullpropeller-rudder system," International Journal of Naval Architecture and Ocean Engineering, vol. 8, no. 6, pp. 589-601, 2016. 
CONTACT WITH THE AUTHORS

Alireza Nadery

e-mail:alireza.nadery33@gmail.com

Amirkabir University of Technology

Hafez, 15785 Tehran

IRAN

Hassan Ghassemi

e-mail:gasemi@aut.ac.ir

Amirkabir University of Technology,

Hafez avenue, Tehran

IRAN 